\title{
Study of rail vehicles movement characteristics improvement in curves using fuzzy logic mechatronic systems
}

\author{
Mikhail Kapitsa ${ }^{1}$, Evgen Mikhailov ${ }^{2,}$, Sergii Kliuiev ${ }^{2}$, Stanislav Semenov ${ }^{2}$, and Maksim Kovtanets ${ }^{3}$ \\ ${ }^{1}$ DNUZT, Department of locomotives, 49010 Dnipro, Lazaryan Street 2, Ukraine \\ ${ }^{2}$ EUNU, Department of logistic management and traffic safety, 93405 Severodonetsk, Central Avenue, 59A, Ukraine \\ ${ }^{3}$ EUNU, Department of railway and road transport, lift and care systems, 93405 Severodonetsk, Central Avenue, 59A, Ukraine
}

\begin{abstract}
The article deals with the effectiveness of reducing the level of force interaction of the rail vehicle wheels with rails in curved sections of the track through the use of mechatronic position control systems for wheel pairs in the rail gauge in the horizontal plane. The approaches to the creation of such a mechatronic system operating on the principles of fuzzy logic are described. To determine the angles of attack of wheels on the rails, it was proposed to use the acoustic emission indicators of the contact of the wheel with the rail. To determine the direction of curvature of the rail track, it is advisable to use data from navigation systems. The study of the dynamics of the rail vehicle during the passage of a curved section of the track in real time was carried out using the Matlab/Simulink software package. The proposed mechatronic control system for the position of the wheel sets in the horizontal plane allows to ensure their optimal installation under various driving conditions in the rail gauge. This makes it possible to minimize the angles of attack of the wheels and reduce the forces of the horizontal interaction of the wheels with the rails.
\end{abstract}

\section{Introduction}

Analysis of the scientific and technical information has shown that the dynamic properties of the rail carriage in the horizontal plane dependent on the speed of its movement, the state of the chassis and carriage track. Wear in the wheel-rail system depends on several factors: the level of forces in the points of contact of the wheels and rails, sliding velocity at these contacts, the values of the angle of attack, the coefficient of friction, hardness, wheel and rail material.

One way of improving the dynamic characteristics of a rail carriage is the rational choice chassis construction [1-4].

Reduction of interaction forces, improved dynamic performance in a curve and a decrease in the wear intensity of rails and flanges may be controlled by wheelset position on the rail track.

\section{Analysis of recent research and publications}

The problem of reducing the interaction forces of the wheels and the rails when driving railway vehicles in the curve explored by I. V. Biryukov, E. P. Blokhin, M. F. Verigo, A. L. Golubenko, N. I. Gorbunov, Y. Demin, S. V. Doronin, V. V. Evstratov, A. A. Kamaev, V. A. Kamaev, V. N. Kashnikov, A. N. Konyaev, M. L. Korotenko, V. S. Koss, S. M. Kutsenko, V. G. Masliev, G. S. Mihalchenko, I. I. Nikolaev, M. L. Radchenko A. M. Savoskin, M. I. Spiryagin, V. I.Spiryagin, V. P. Tkachenko and etc.
The basic requirements that apply to new railway vehicles are to increase traffic safety and decrease the level of dynamic interaction with the rail.

Passage curves passing is accompanied by an increase of wheels wear and rails intensity [5 - 10]. Important areas of reduction of wear in curves is the application of lubricant on the contacts of the wheels with the rails and reduction of forces acting on them, reducing efforts and guides the angle of attack (due to the choice of optimal circuit parameters and spring suspension of railway vehicles) $[2,13,14]$.

One of the most promising ways to reduce the rate of wear in the "wheel-rail" is to use rational constructions of railway vehicles, supplemented with active position control system wheelset in curve [11 - 12].

To determine how to control the position of the wheelset on the rail track, it is necessary to know the characteristics of the controlled object and the noise coming into the control unit.

Railway vehicle control system can be divided into two groups (Fig. 1.)

1) The passive control system, allowing to change the kinematic scheme depending on how (straight or curved) it is moves;

2) The active control system, which curves have a force effect of adjusting the wheelsets angle of attack on the rails and minimizing lateral force.

Active control systems are the most advanced solutions for the problems of wear of wheel sets.

In the low speed range, the efficiency of mechatronic systems determined by the decrease of resistance to

Corresponding author: sergistreet@gmail.com 
motion and wear in the wheel-rail contact. In the range of high speeds, special attention should be focused on the stability of the motion of wheel pairs in the horizontal plane.

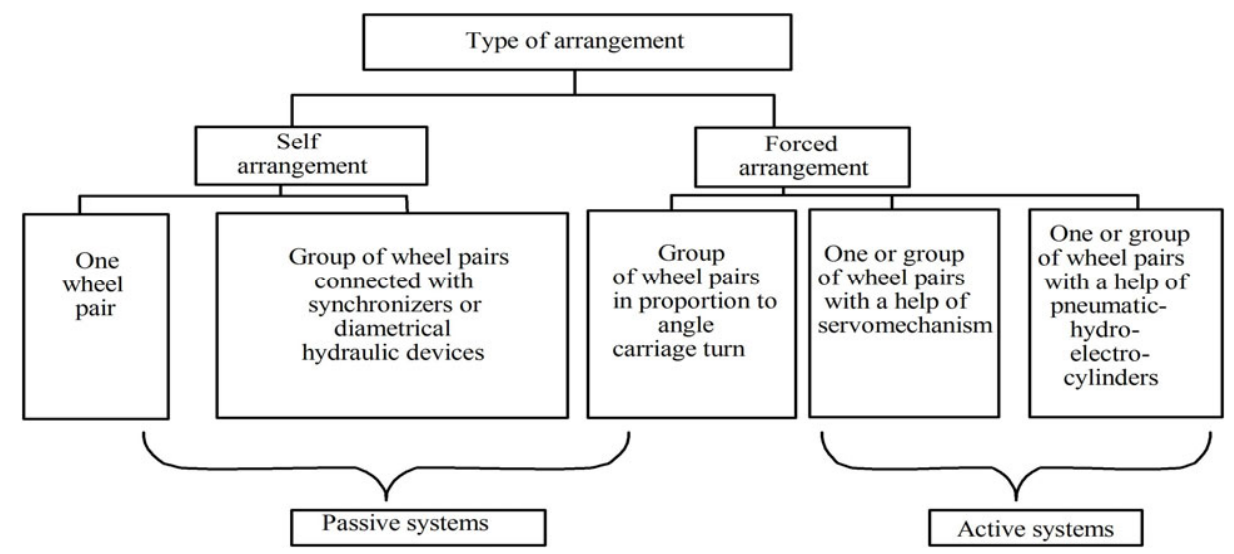

Fig. 1. Classification of device for radial wheel sets installation in curve

For the development of modern microprocessor technology, it becomes possible to use mechatronic control systems operating on principles of expert systems, fuzzy logic, neural networks, associative memory and others.

Table 1 shows the results of analysis techniques and algorithms of existing mechatronic control systems.

Table 1. Construction of mechatronic systems for forced rotation of the wheelset

\begin{tabular}{|c|c|c|}
\hline \multicolumn{3}{|c|}{ Mechatronics system } \\
\hline \multirow{2}{*}{$\begin{array}{c}\text { object of } \\
\text { control }\end{array}$} & \multicolumn{2}{|c|}{ Control system } \\
\hline & control principle & way of management \\
\hline $\begin{array}{c}\text { traditional } \\
\text { pair of wheels }\end{array}$ & $\begin{array}{l}\text { feedback, the } \\
\text { principle of } \\
\text { feedforward }\end{array}$ & $\begin{array}{l}\text { Optimal control, optimal } \\
\text { control with genetic } \\
\text { algorithm, linear-quadratic } \\
\text { Gauss control, proportional } \\
\text { control, sliding mode control, } \\
\text { fuzzy logic, proportional- } \\
\text { integral controller }\end{array}$ \\
\hline $\begin{array}{c}\text { Wheel set } \\
\text { with } \\
\text { independent } \\
\text { wheel rotation }\end{array}$ & $\begin{array}{l}\text { the principle of } \\
\text { feedback }\end{array}$ & $\begin{array}{l}\text { proportional, integral and } \\
\text { differentiating control, } \\
\text { adaptive control, robust } \\
\text { control, optimal control }\end{array}$ \\
\hline
\end{tabular}

Currently, the most important is the use of mechatronic solutions for traditional wheel sets, which are widely used in railway transport. Further development increases the need for technologies mechatronic systems for wheel sets with independently rotating wheels. Currently, the construction of railway vehicles with independently rotating wheels (IRW) is not yet widely available, although work in this direction is actively underway.

Studies show that when using wheel sets with IRW missing their centering in the rail track. In this regard, there is a long ridge overrunning of one of the wheels on the rails and an increased level of wear and motion resistance $[8,22,27]$. Therefore, while the design of the chassis with independently rotating wheels are used, mainly in urban rail carriages with low floors, where the wheel flange wear is small due to low speed and small load axis [22, 23].
In the case of such structures on the main rail transport is necessary to adopt additional measures to ensure the self-centering of wheel sets in rail track. Of the few examples of practical applications they can be called bogies Talgo system operated quite successfully for several decades because of the original concept direction wheel sets in a track [24].

Certain reduce slippage wheel flanges on the rails can be achieved by improving the design schemes of the wheels themselves, for example, by allowing the independent rotation of the supporting and guide surfaces $[25,26]$.

Also investigated a limited possibility of wheel rotation in a wheel pair relative to each other through the use of innovative designs axle and wheel mounting thereon units $[8,22,23]$.

One of the most currently developed areas of railway vehicles with IRW dynamics improvement, reduce wear of wheels and rails and driving resistance is using of mechatronic systems for controlling the position of wheel pairs with IRW in the rail track in a horizontal plane. The results of numerous theoretical and experimental studies [28-30] confirm the effectiveness of this approach.

One way to reduce the horizontal transverse forces arising during the passage of railway vehicles of the curves is to provide a controlled motion wheel sets [15].

It was theoretically and experimentally proved that traditional solutions and passive methods have already reached their capabilities, and further reducing the solution to the problem of wear and the force interaction may be accomplished by using of active control systems. The algorithm of such a control system is that the wheel set turning in a horizontal plane on a railway line at an angle with the motion of the actuator curve to minimize the angle of attack of wheels on the rail [16].

Control action on wheel pairs opens up new possibilities to improve quality of the dynamics on curve, reduces dynamic influence on the rail and wear. However, existing control systems radial wheel set installation until providing the necessary wheel on the rail angle of attack control, due to the complexity of the measurement of this parameter [15]. 


\section{The purpose of the study}

The aim of the article is to examine the impact on the reduction of the force interaction of railway vehicles and the rail wheel set mechatronic position control system of the rail track, operating on the basis of fuzzy logic.

\section{The results of the railway vehicles dynamics study in the curve}

A disadvantage of existing devices wheel set turning in the horizontal plane is the absence of the automatic position control of the wheel set on the track. Therefore, it is advisable to create a high-speed active control system of the position of the wheel set on the track is not on the basis of operational parameters of movement, but with the control wheel angle of attack on the rail and the direction of movement in a curve.

The authors proposed to use the audio signal system setting for radial wheel pairs installation based on parameters of the contact wheel pair and operating on fuzzy logic principles.

Automatic control of the position of wheel set on the track should provide:

- stabilizing the motion of the wheels et in straight sections of the track (increase in wavelength yaw);

- minimizing the interaction forces between wheel set and rails;

- handling and uniqueness.

Additional requirements to the system of automatic control of the position of the wheel set on the track:

- the presence of anti-aliasing in the subsystem "state variables - active management";

- reliable operation in a predetermined mode for a predetermined period of time;

- reliable and correct functioning in an emergency such as a power failure and subsequent recovery, blown fuses, broken wires;

- the content of the minimum possible number of components and a minimum possible length of the connecting wiring lines.

Using the pulling device (drive: pneumatic, hydraulic, electromechanical) pair is transmitted to the wheel force control. The most important issue in the construction of an algorithm controlling the position of the wheel set on the track is to determine the time the driving force for changing and the establishment of control algorithm of this magnitude.

As shown in [17] for radial installation of the wheel set in a rail track necessary to ensure the equality of the longitudinal wheel traction forces on a single axis (or zero power in the case of rolling without traction or braking) and the equality of lateral cohesion forces for all wheel sets rail vehicle. This can be achieved if the angle of attack for the two wheel sets (for example, biaxial carriage) can be adjusted and is equal, and if the carriage moves along the central axis in the track curve. This can be achieved by setting equal angles of rotation of wheel sets relative to the bogie frame. But it is almost impossible to achieve in real-world conditions such equality of angles [18]. Therefore, the mechatronic control system was designed to force the wheel sets. In the proposed system the forced radial setting of the wheel set by means of additional actuators whose operation is controlled by a microprocessor system (see. Fig. 2) by a special algorithm. The proposed model takes into account the parameters of the acoustic emission from the wheels in contact with the rail, obtained experimentally [4].

In this algorithm analyzes the acoustic signal parameters of the wheels in contact with the rail for determining the value of the angle of attack. In this position of the vehicle on a track section recorded in accordance with the data of GPS system. Also takes into account the lateral position of the wheel set relative to the track and the rotation angle of the carriage with respect to the vehicle body.

Regulator regulating effect is formed with the curvature direction on the track section. The angle of attack is determined by the corresponding displacement of the actuator stem.

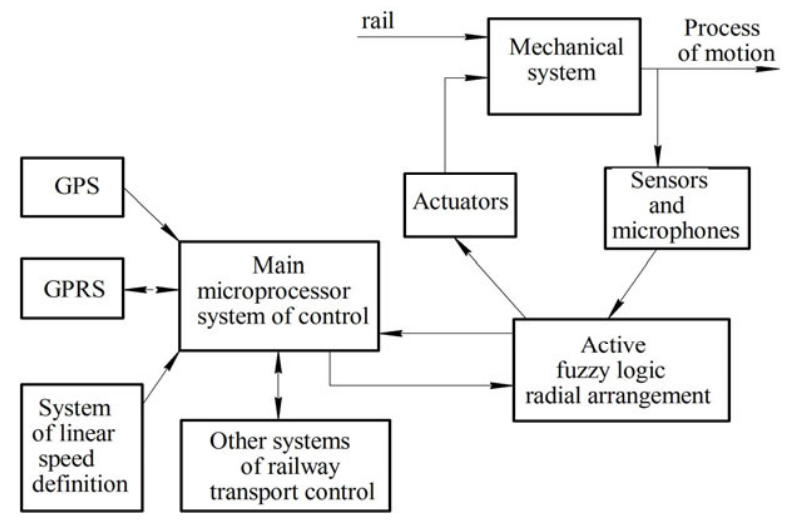

Fig. 2. The mechatronic system radial installation of wheel sets

To simulate the interaction of the rail carriage with a rail track has been selected Matlab/Simulink simulation environment. Mae T., Lee $\mathrm{H}$ assumptions were taken to initial prerequisites for creating the model. [3]

Basic mechatronic control system generates a control action for turning the wheel pair in the horizontal plane of the track at an angle which minimizes the angle of attack of wheels on the rail or shift to a non-contact motion with the rail head.

The control circuit with a feedback controller operating according to the principles of fuzzy logic, is shown in Fig. 3.

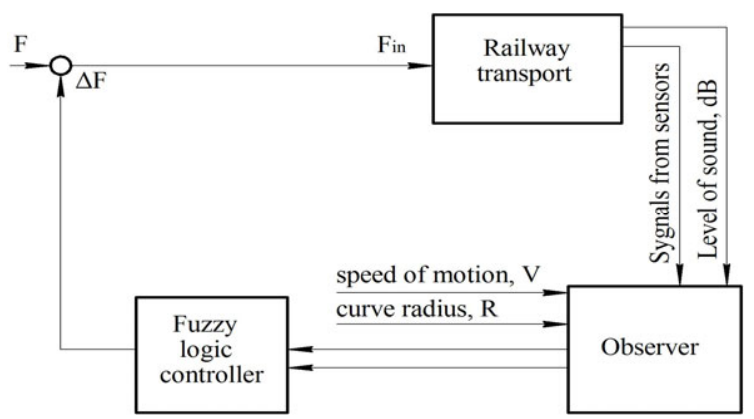

Fig. 3. The control circuit of the controller using fuzzy logic for the wheel set control active position 
Where $\mathrm{F}$ - force value, which is realized in the drive certain initial moment. The value of this force can be obtained for a particular observer in a special database curve. The database may be generated based on theoretical studies. In our case, the value of the force $\mathrm{F}$ is set and depends on the curve radius $\mathrm{R}$ and the velocity $\mathrm{V}$. The next value of the force depends on the time when $F(t)$ should be equal to the previous value of the force.

The corrected value for $\Delta \mathrm{F}$ drive force can be obtained in accordance with fuzzy logic rules. With the use of the mechanical system analysis and numerical methods for solving the problem of optimal choice made state variables - the difference between the ideal and the calculated angle of rotation of the wheelset relative to the bogie frame.

One of the problems in developing a fuzzy logic control system is to obtain information about the angle of attack of the wheel set on the rail. Existing methods for determining the angle of attack without installing a stationary sensor on the rail base is used for indirect measurement and calculation of the angle of attack do not allow to measure it in real time and automatically.

The possibility of determining the angle of attack of a wheel set on the rail on the basis of acoustic emission method is observed. In order to explore the use of acoustic radiation from the contact rail-wheel for determining the angle of attack on the rail wheels have been carried out experimental studies of the mechanism of generation of the acoustic signal in this contact $[19$, 20]. Experimental studies were carried out on the model of the roller station and locomotive 2TE116.

It proved experimentally that the acoustic emission spectrum is not identical. At certain frequencies of sound pressure level is significantly higher than the average equivalent sound pressure level.

According to the experimental studies, based on the parameters of the acoustic emission from the wheels in contact with the rail was installed informative feature and the experimental dependence of the sound pressure level of deviation has been obtained on the dominant frequency of the equivalent sound pressure level at different angles of attack on the rail wheels.

The functional dependence of the sound pressure level of the angle of attack on the acoustic emission dominant frequency was used to determine the angle of attack of wheels on the rails when forming the control cylinder impact to the wheel of a rail vehicle when traveling on curve.

Determination of the dominant acoustic emission frequency of the wheel-rail contact was made using a signal processing algorithm using wavelet transformation using a wavelet function for any moment of time t. According to statistical data of sound pressure level depending on the angle of attack on the rail wheels was performed neuro-fuzzy adaptation, based on which set of rules has been received and the surface to determine the wheels on the rail angle of attack.

To receive the digital sequence was performed wavelet transformation using a wavelet function for the different moments of time $t$.

Wavelet transformation:

$$
W_{\mathrm{f}}(t, a)=(1 / \sqrt{\mathrm{a}}) \cdot \int \Psi[(x-t) \mathrm{a}] \cdot f(x) d x
$$

where $f(x)$ - is the research signal; $\Psi(x)$ - is a waveletfunction; $\Psi(x)=(\cos x+i \cdot \sin x) \cdot e^{-x 2 / 50} ; t-$ is the time; and $a-$ is a scale of wavelet-function.

The frequency spectrum obtained by processing acoustic emission signals in accordance with the algorithm of fast Fourier transform.

However, the acoustic method for determining the angle of attack can not determine the direction of movement (the angle mark). Determining the direction of the curve on the section of track seems reasonable if you use satellite navigation and inertial system [21].

Joint processing of the calculated coordinates carried by the synchronization signals from the satellite receiver and the inertial unit. Improving the accuracy was achieved through the suppression of errors in each system.

Scheme joint operation of the satellite receiver and the inertial unit shown in Fig. 4.

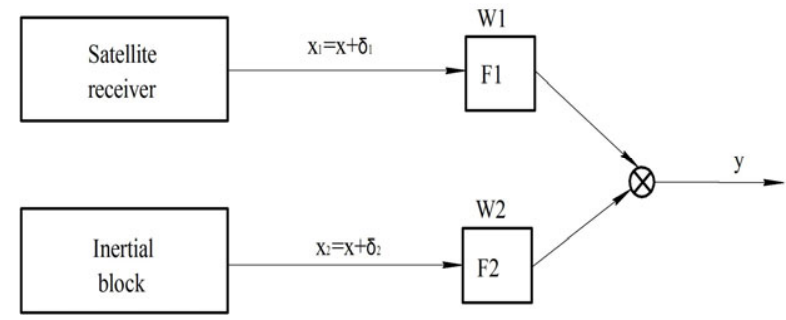

Fig. 4. Block diagram

Where $\mathrm{y}$ - coordinate of the crew location; W1, W2 filter transfer functions; F1, F2 - filters; $\mathrm{x} 1, \mathrm{x} 2-$ representation of the desired signal $\mathrm{x}(t) ; \delta 1$ and $\delta 2-$ view satellite receiver errors and inertial unit

$$
\begin{gathered}
y=(\mathrm{W} 1+\mathrm{W} 2) \cdot x+\mathrm{W} 1 \cdot \delta_{1}+\mathrm{W} 2 \cdot \delta_{2} \\
\delta_{1}(T)=\mathrm{b}+\mathrm{m} \cdot \sin (n \cdot t)
\end{gathered}
$$

where $\mathrm{b}$ - is a permanent part (constructive error); $\mathrm{m}$ - is an amplitude of dynamic error; $\mathrm{m} \cdot \sin (n \cdot t)$ - is a highfrequency constituent of error (dynamic error), $\mathrm{n}-$ is angular frequency of vibrations, $\mathrm{t}-$ is the time.

$$
\delta_{2}(T)=\mathrm{r} \cdot \mathrm{t},
$$

where $r$ - is the average speed of inertial block drift.

As for the input and output variable defined triangular and trapezoidal functions properties because they are simple and common in use. Group of linguistic rules used to form the input and output variables. This group includes tags: $\mathrm{N}$ and $\mathrm{P}$ - negative and positive values, respectively; $\mathrm{S}, \mathrm{M}$ and $\mathrm{B}$ - small, medium and large values, respectively; $\mathrm{ZE} \mathrm{-} \mathrm{mean} \mathrm{value} \mathrm{equal} \mathrm{to}$ zero. Parameter ranges can be obtained either from experimental data, or from simulation results. The ranges of the input variables obtained from the results of the quasi-static forces analysis for basic carriage.

Following a set of rules (Fig. 5) was selected for the simulation of fuzzy logic system.

Actuator function control is required to turn the wheel pair is shown in Fig. 6.

A set of rules for the proposed fuzzy logic systems with fuzzy logic controller is shown in Table 2. 


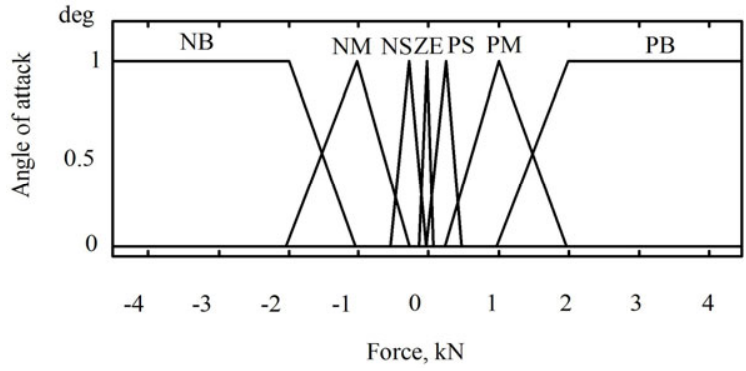

Fig. 5. Function of property variable difference between the ideal layout and the measured angles of the wheel set: $\mathrm{NB}$ - negative big, NM - negative medium, NS - negative small, ZE - zero, PS - positive small, PM - positive medium, $\mathrm{PB}$ - positive big

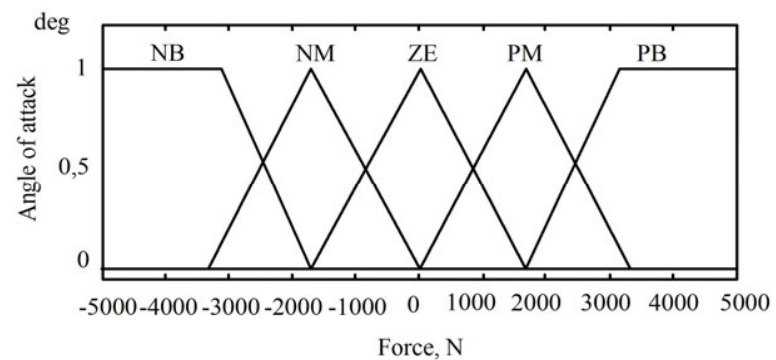

Fig. 6. The function variable values drive efforts properties: $\mathrm{NB}$ - negative large, NM - negative mean, ZE - zero; PM positive average, $\mathrm{PB}-$ positive big.

Table 2. A set of rules for the fuzzy logic controller

\begin{tabular}{|c|c|c|c|c|c|c|c|}
\hline \multicolumn{1}{|c|}{$\gamma_{\text {IDEAL }}-\gamma$} \\
\hline & NB & NM & NS & ZE & PS & PM & PB \\
\hline$\Delta \mathrm{F}$ & NB & NM & NS & ZE & PS & PM & PB \\
\hline
\end{tabular}

\section{Discussion of the research results of railway vehicle dynamics in a curve controlled on the basis of fuzzy logic}

Theoretical study of movement of the locomotive type 2TE116 model track curve performed on the original

Stock system
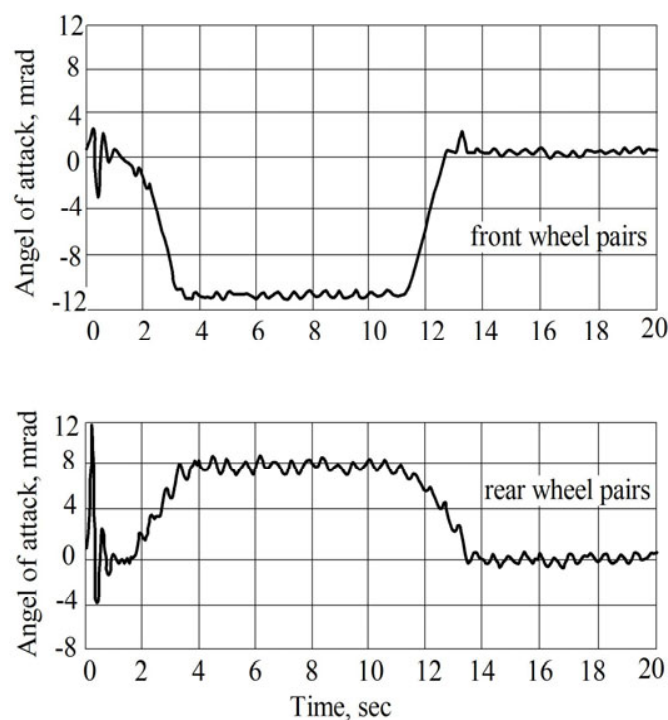

data, which correspond to the parameters of the experiment shown in [20].

Result comparison of the modeled locomotive movement of serial 2TE116 and locomotive with a fuzzy logic control system of the wheel sets on a curve with a radius of $300 \mathrm{~m}$ at a speed of $70 \mathrm{~km} / \mathrm{h}$ are shown in Fig. 7 . For a system simulation used the same output data and the simulation technique, which are applied in Iwnicki [19].

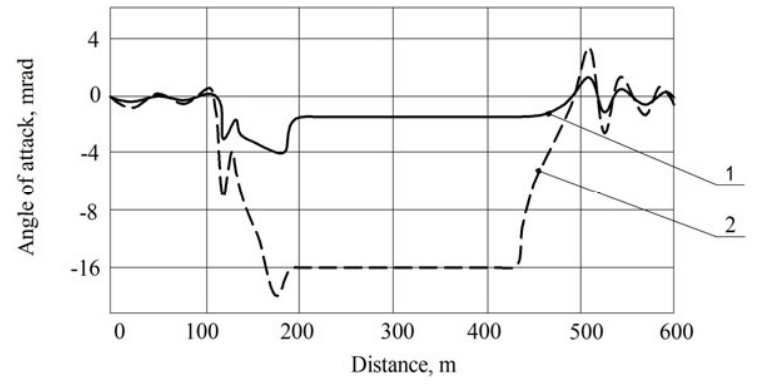

Fig. 7. The theoretical values of first wheel set angle of attack of the 2TE116 locomotive at a controlled and uncontrolled locomotive motion on curve $(\mathrm{R}=300 \mathrm{~m}, \mathrm{~V}=70 \mathrm{~km} / \mathrm{h})$ : 1 - controlled movement; 2 - uncontrolled movements

Work proposed mechatronic system was also tested in the simulation carriage movement with the main parameters diesel train type DEL-01.

To create a non-linear simulation model of diesel train traffic software Simpack was used. The proposed method of controlling the forced installation of the wheel sets has been implemented in a software product Matlab/Simulink. A vehicle model created in Simpack, was associated with a control system designed in Matlab/Simulink, using SIMAT interface that is used for both special modeling software packages.

Fig. 8, 9 show the values obtained for wheel angles of attack and lateral movement of the front and rear wheel pairs as a function of distance traveled for standard design and construction with the mechatronic bogie wheel sets active setting.
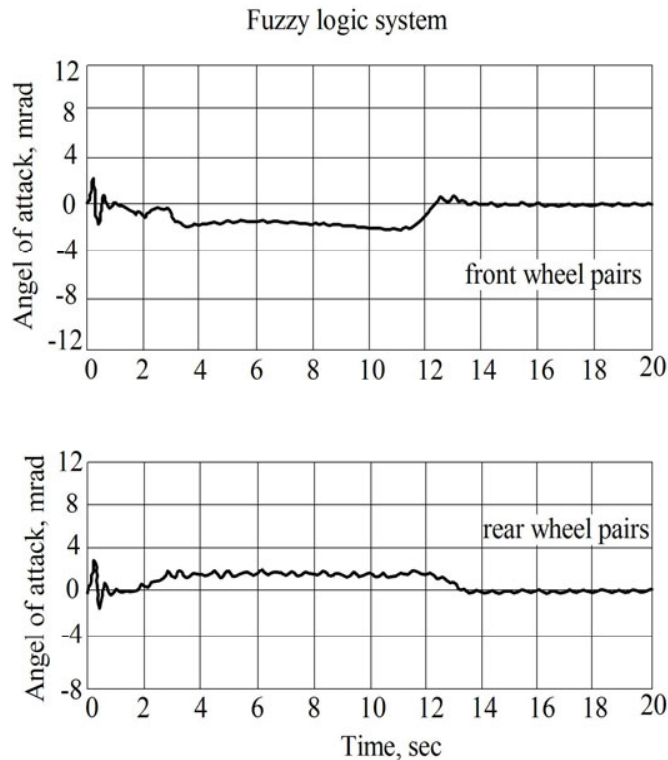

Fig. 8. Results diesel train movement simulation DEL- $01(\mathrm{R}=300 \mathrm{~m}, \mathrm{~V}=90 \mathrm{~km} / \mathrm{h})$ 

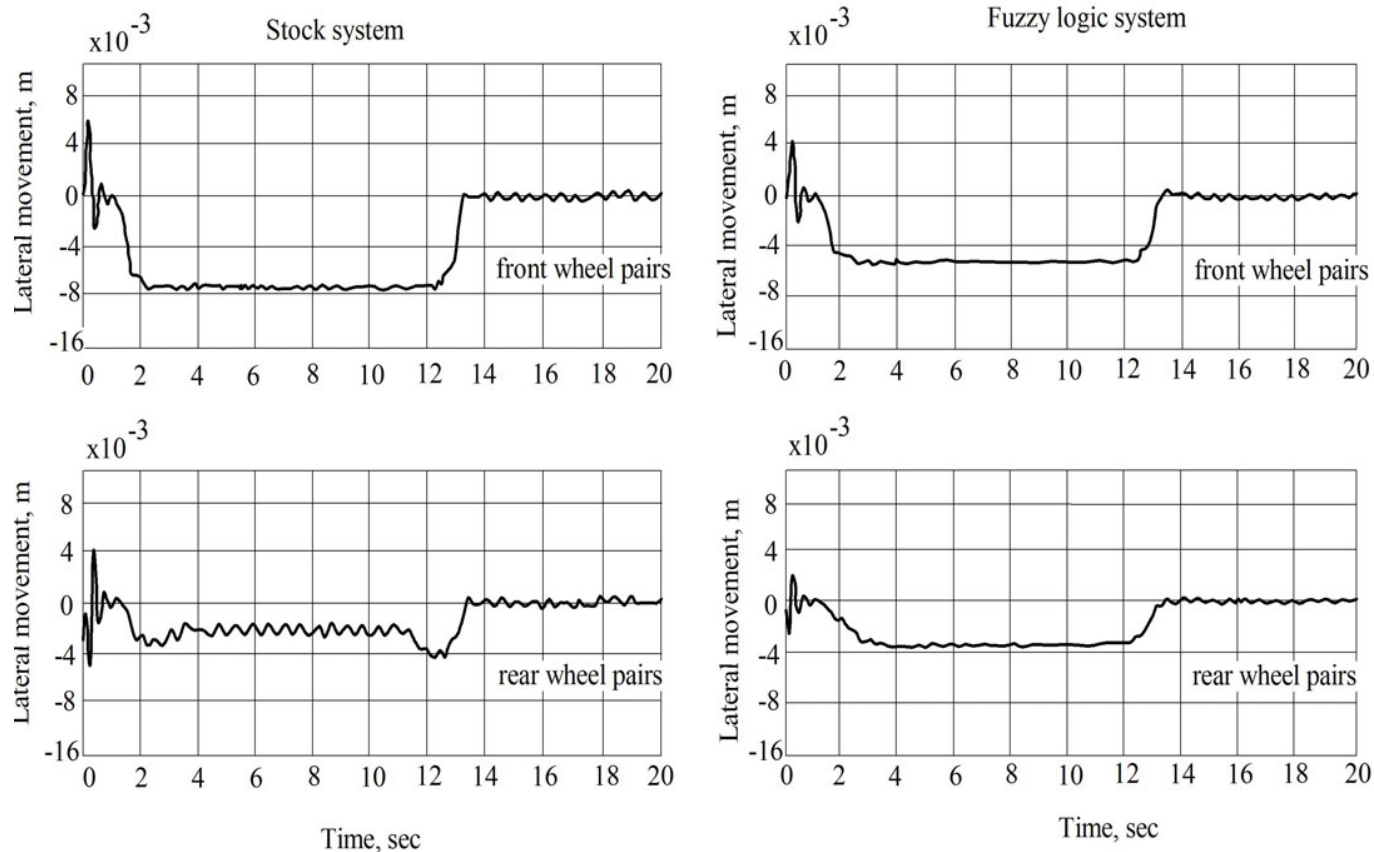

Fig. 9. Results of a diesel train DEL-01 motion simulation $(\mathrm{R}=300 \mathrm{~m}, \mathrm{~V}=90 \mathrm{~km} / \mathrm{h})$

\section{Conclusions}

Presented mechatronic active position control system of a rail wheel pair in the track allows to obtain its optimum setting for different modes of a rail carriage motion, thereby reducing the forces on the guides for $35 \%$ and to minimize the angle of attack to zero. Fuzzy logic control allows to provide efficient management of complex mechatronic system and has advantages as compared with control by proportional control. Using of fuzzy logic in this case is allow to avoid the creation of a complex mathematical model for the simultaneous actuators using of each wheel set.

One of the methods for wheel set relative to the rail position evaluating is to use acoustic emission parameters from contact of wheels with the rails. For practical use of this method it is necessary to create an appropriate database, depending on the characteristics of a rail carriage motion, part of railway track and friction conditions in contact.

\section{References}

1. V. Ulshin, S. Klyuev, E. Zubar, Metod avtomaticheskogo kontrolya ugla nabeganiya kolesa na rels. Visnik SNU im. V.Dalya. Lugansk, 4 (193), 259-262 (2013) [in Russian]

2. S. Klyuev, A. Klyuev, Metodiki aktivnogo upravleniya telezhkoy relsovogo transportnogo sredstva. Visnik SNU Im. V.Dalya. Lugansk, 4 (134), 67-74 (2009) [in Russian]

3. T. Mei, H. Li, Control design for the active stabilization of rail wheelsets, Journal of Dynamics Systems, Measurements and Control, 130 (2008)

4. H. Scheffel, H. Tornay, The mechanism of the rotable lemniscate suspension applied to bogies having selfsteering wheelsets, Vehicle System Dynamics, 17, 368-380 (1988)
5. A. Teplyakov, Puti snizheniya intensivnosti iznosa grebney kolesnyih par lokomotivov: Diss. kand. tehn. nauk, Habarovsk, 197 (2004) [in Russian]

6. B. Kossov Snizhenie nagruzhennosti hodovyih chastey lokomotivov i puti. Avtoreferat diss. dokt. tehn. Nauk, Kolomna, 339 (2001) [in Russian]

7. A. Golubenko, A. Kostyukevich, I. Tsyganovskiy, V. Nozhenko, The influence of a rail lateral bending on the stress - strain state of a wheel - rail contact, TEKA Commission of Motorization and Power Industry in Agriculture, 11a, 78-84 (2011)

8. A. Golubenko, Stseplenie kolesa s relsom: Monografiya, 2-e, pererobl. ta dop. Lugansk, 476 (1999) [in Russian]

9. V. Vasin, V. Berezin, A. Kokorev, V. Nadelyuev, Effektivnost radialnoy ustanovki kolesnyih par shetiosnogo lokomotiva. Problemyi razvitiya lokomotivostroeniya. Lugansk, 26 (1990) [in Russian]

10. S. Bruni, R. Goodall, T. Mei, H. Tsunashima, Control and monitoring for railway vehicle dynamics, Vehicle System Dynamics, Ed. 45, 733-779 (2007)

11. J. Choi, S. Park, J. Kim, Dynamic adhesion model and adaptive sliding mode brake control system for the railway rolling stocks, Proc. IMeche Part F: J. Rail and Rapid Transit, 221, 313-320 (2007)

12. M. Spiryagin, V. Spiryagin, I. Kostenko, Modelling of a controlled tractive wheelset for a bogie of a railway vehicle based on noise spectrum analysis, TEKA Commission of Motorization and Power Industry in Agriculture, 11a, 232-244 (2011)

13. D. Nyuland, Upravlyaemost podatlivoy zheleznodorozhnoy telezhki na krivolineynom uchastke puti. Konstruirovanie i tehnologiya mashinostroeniya, 3, 365-375 (1969) [in Russian]

14. I. Kirichenko, A. Kashura, M. Kashura, Design of process of friction of rolling with sliding, TEKA Commission of Motorization and Power Industry in Agriculture, 8a, 6371 (2008)

15. M. Guskova, V. Ruban, Parametryi konstruktsii podvizhnogo sostava $i$ puti, vliyayuschie na podrez 
grebney bandazhey kolesnyih par lokomotivov // Vestnik RGUPS. Rostov, 2, 32-35 (2000)

16. R. Goodall, S. Bruni, T. Mei, Concepts and prospects for actively-controlled railway running gear. Vehicle System Dynamics, 44 (suppl), 60-70 (2006)

17. S. Iwnicki, Handbook of Railway Vehicle Dynamics, CRC Press, UK (2006).

18. V. Masliev, Nauchnyie osnovyi vyibora konstruktorskotehnologicheskih parametrov ustroystv dlya umensheniya iznosa bandazhey koles lokomotivov, Diss. dokt. tehn. nauk, HPI, Harkov, 497 (2001) [in Russian]

19. V. Spiryagin, S. Klyuev Eksperimentalnoe issledovanie zvukovogo signala, ispuskaemogo s kontakta koleso-rels pri razlichnyih usloviyah ih vzaimnoy ustanovki. Zb. (MehTriboTrans-2011)", Rostov-na-Donu, 214-217 (2011) [in Russian]

20. M. Spiryagin, Soo L. Kwan, Hee Y. Hong, V. Spiryagin, S. Klyuyev, Study on using noise for development of active steering control system of rail vehicle. Proceedings of the 23nd National Conference and Exposition on Noise Control Engineering (Noise-Con 2008), 28-31 July 2008, Dearborn, Michigan. USA. Curran Associates, Inc., 499506 (2009)

21. V. Spiryagin, S. Klyuev, E. Zubar, Vyibor metoda opredeleniya koordinat mestopolozheniya lokomotiva pri upravlyaemom dvizhenii kolesnyih par $v$ relsovoy kolee. Visnik SNU im. V. Dalya. Lugansk, 5 (194) Ch. 2, 144146 (2013) [in Russian]

22. Marcel Ujfaluši. How can design of wheelsets improve future rolling stock performance? Global Railway Review. Issue 5, September 10 (2016)

23. A. Bracciali, "Railway Wheelsets: History, Research and
Developments", International Journal of Railway Technology, 5 (1), 23-52, doi: 10.4203 / ijrt.5.1.2 2016 (2016)

24. Talgo. [Electronic resource]. - Access Mode: https://www.talgo.com/

25. E. Mikhailov, S. Semenov, V. Tkachenko, S. Sapronova, Reduction of kinematic resistance to motion of the railway vehicles. MATEC Web of Conferences 235, 000 Horizons of Railway Transport, 33-40 (2018)

26. A. Shiler, Analysis and simulation of new wheel pair construction. Proceedings of the 25th DAAAM International Symposium Procedia Engineering. Vienna. Austria, 1714-1723 (2014)

27. V. Tkachenko, S. Sapronova, I. Kulbovskii, O. Fomin, Research into resistance to the motion of railroad undercarriages related to directing the wheelsets by a rail track. Eastern-European journal of enterprise technologies. Kharkiv, PC «Technology center». 5/7 (89), 65-72. (2017)

28. J. Perez, J. Busturia, T. Mei, J. Vinolas, Combined active steering and tract in for mechatronic bogies vehicles with independently rotating wheels. IFAC Mechatronic Systems, 737-742 (2002)

29. D. Derbyshire, Development of an intelligent sensing technique for active control of railway vehicles with independently rotating wheels. Manchester Metropolitan University. A thesis for the degree of Master of Philosophy, 87 (2015)

30. N. Farhat, P. Ward Christopher, Roger M. Goodall, Roger Dixon. The benefits of mechatronically-guided railway vehicles: A multi-body physics simulation study. Mechatronics. 51, May 2018, 115-126 (2018) 